\title{
Pilot study on secondary effluent of printing and dyeing wastewater by lignite-coke BAF
}

\author{
Xin Jin, Jilin Teng, Ruozheng Li, Can Wang \\ Beijing GuoDianFuTong Science\&Technology Development Co., Ltd. \\ ABP 6-14 Building, No.188 Nansihuan Xi Road, Fengtai District,Beijing 100070, China \\ frankjinxin@126.com
}

Keywords: Lignite-coke; BAF; Printing and dyeing industry; Tail water

Abstract. The secondary effluetn of Printing and Dyeing industry wastewater is a typical low load and refractory wastewater. The COD concentration is between $150-200 \mathrm{mg} / \mathrm{L}$. In this pilot study, the treatment effect of lignite-coke and ceramic filter BAF was investigated. By comparison with the laboratory scale test and parameter optimization, lignite-coke filter take obvious advantages on the terms of bleaching and biological biofilm. After several months of continuous lignite-coke BAF pilot operation, the results show that: the removal rate of COD beyond $50 \%$ under the condition of volume ratio $10: 1$ for gas to water, hydraulic loading is $0.2 \mathrm{~m}^{3} / \mathrm{m}^{2} \mathrm{~h}$, , the COD concentration of effluent is below $50 \mathrm{mg} / \mathrm{L}$ and colorless, can reach the requirements of design. Lignite-coke BAF has a good prospect of industrialized application.

\section{Introduction}

The production capacity of a south county's textile industry is more than $30 \%$ of the total output. Printing and dyeing industry is a high energy consumption and high pollution industry. With the high concentration of environmental problems, the raising utilization ratio of water resources and decreasing of wastewater discharge is necessary, so the reuse of tail water by advanced treatment is urgently.

The biological aerated(BAF) filter is the most widely used in advanced treatment process, filter is the base and key impact factor in BAF operation. Activated carbon, ceramsite and volcanic rocks is the commonly used filter. Activated carbon is expensive compare to ceramsite and volcanic rocks while the adsorption and microbial carrier capacity of ceramsite and volcanic rocks is weak. Lignite-coke is a new type of biological filter material in recent years. It has obvious advantages over the terms of adsorption macromolecular organic matter and decoloring. This study focuses on lignite-coke aeration biological filter, inspects on different physical and biological properties of filter, monitors the efficiency of filter processing, carrys out small-scale tests on the basis of the pilot test, optimizes and adjusts the process parameters, provides supports in dealing with the tail water of dyeing and biochemical engineering applications using lignite-coke BAF. 


\section{Materials and methods}

\section{Experimental flow chart}

Experiments process was shown in Fig.1。

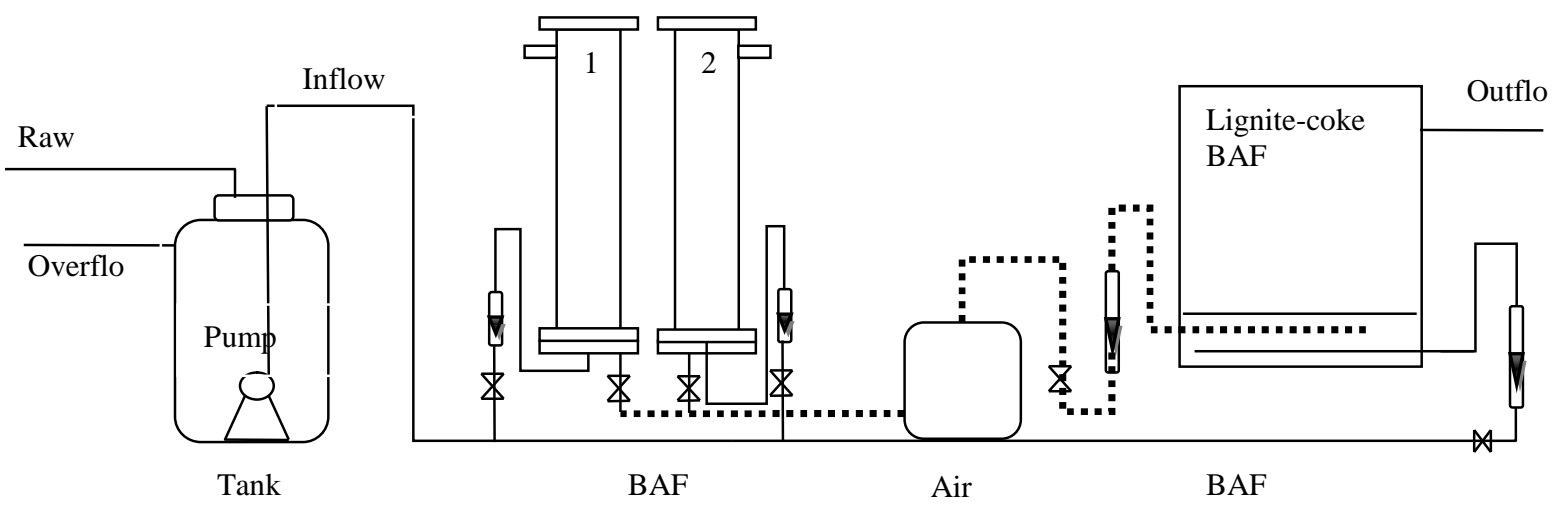

Fig.1 Experimental process

\section{Laboratory instruments and equipment}

(1)Raw water tank, volume: $3.0 \mathrm{~m}^{3}$

(2) Organic glass filter reactor, filter height: $1.5 \mathrm{~m}$

(3) Pilot scale equipment, volume: $7.17 \mathrm{~m}^{3}$, filter height: $1 \mathrm{~m}$

\section{Test methods}

Experiments in two parts: Lab scale experiments and pilot scale test. Lab-scale experiments

Using two different kinds of lignite coke and ceramsite in filter, particle size is $3 \sim 8 \mathrm{~mm}$, carry on parallel comparison test. Biological filter column design flow is $1.0 \mathrm{~L} / \mathrm{h}$, empty bed residence time is $8 \mathrm{~h}$, filter height is $1.5 \mathrm{~m}$.

Large-scale test

Start running stage from 150 to $200 \mathrm{~L} / \mathrm{h}$ of the flow of continuous water of biological aeration filter, control the intake air quantity of $2.0-2.2 \mathrm{~m}^{3} / \mathrm{h}$ of BAF. After the domestication for a period of time in the cultivation, according to the actual operation situation to adjust the water flow rate and air gradually to meet the design requirements, empty bed residence time is $5 \mathrm{~h}$, filter height is $1 \mathrm{~m}$.

The test runs about 7 month totally from March 16, 2012 to October 13, 2012.

\section{Results and discussion}

The analysis of performance of lignite-coke filter

The decolorization effect of lignite-coke

Compared with the effect of the treated water after two different filter, ceramic and lignite coke filter both has a better removal effect to the color of the raw water. And the lignite-coke filter column has a more obvious decolorization, the treated water is colorless substantially. The main reason is the lignite coke contains a large number of pore structure, which have a better adsorption large to the molecular weight of dyeing wastewater color groups, so it can achieve a better effect of discoloration. 


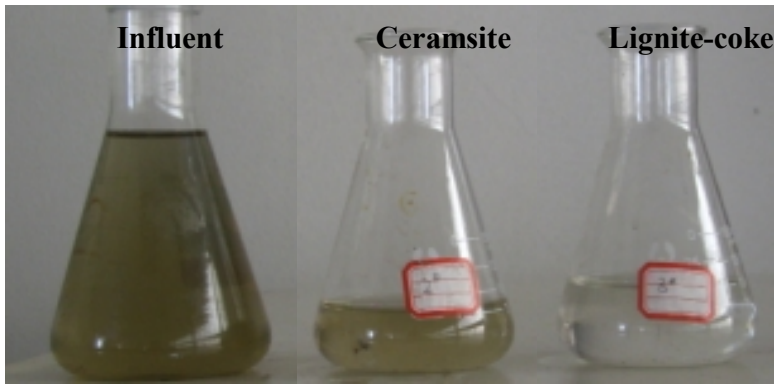

Fig.2 comparison of the effect of different filter media

The performance of biofilm

For the filter, its compactness, interception and expansion of these indicators are important factors related to filter performance and biofilm aeration culture. The effect of biofilter filter and biofilm in the biological phase is not only closely related to culture conditions of domestication, but also related to the structure and the characteristics of filter material. Inoculated lignite sludge to two filter column observed at the bottom after 30 minutes aeration approximately, to observe the compactness; Pumped into approximately $200 \mathrm{~mL}$ to the two columns from the bottom of the filter using a peristaltic pump, observed the situation of sludge trapped after 3 hours aeration; Consecutive two days by aeration, filtration column expansion was observed. Fig. 2 respectively show the compared result of ceramic filter and the lignite coke filter in compactness, interception and expansion and other aspects.

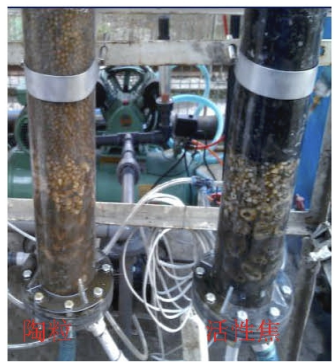

(a) compactness

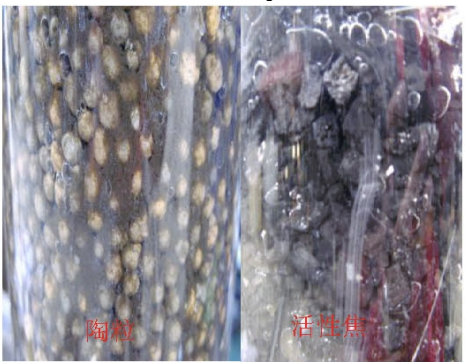

(b) withholding

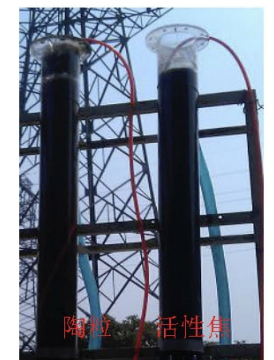

(c) expansibility

Fig.3 filter material surface biofilms

Diagram (a) showed that there was an obvious sludge sink in the ceramsite filter column supporting layer, which through the retainer layer and reached with water, but lignite coke packing lignite sludge was concentrated in the filter column packing, retainer, only a small amount of powdered lignite-coke was found the sludge, which can account for the lignite coke packing density is better than that of ceramsite filler. (b) show that the sludge has obvious heterogeneity between ceramsite distribution, more suspended sludge is found in supernatant fluid after a period of aeration, water, and withholding is poorer to sludge, but lignite coke filter column found no significant between activated coke particles in the sludge.(C) suggests that ceramsite filter column packing height did not change obviously through continuous aeration, and lignite coke filter column filler loading height decreased from $1.2 \mathrm{~m}$ to $1.1 \mathrm{~m}$, how much bubble is analyzed from a filter pillars, the bubble in the lignite coke filter is significantly less than the ceramsite filter column on pillars. After a period of train, it can be seen there are a lot of microbes with biological activity in the biofilm, by further observation of lignite coke filter material with a microscope, as shown in figure 3, the microorganisms in the biological filter column is in good condition, and has a high activity, it also can better to degradation and removal of pollutants, which means on the degradation of pollutants in sewage removal. 


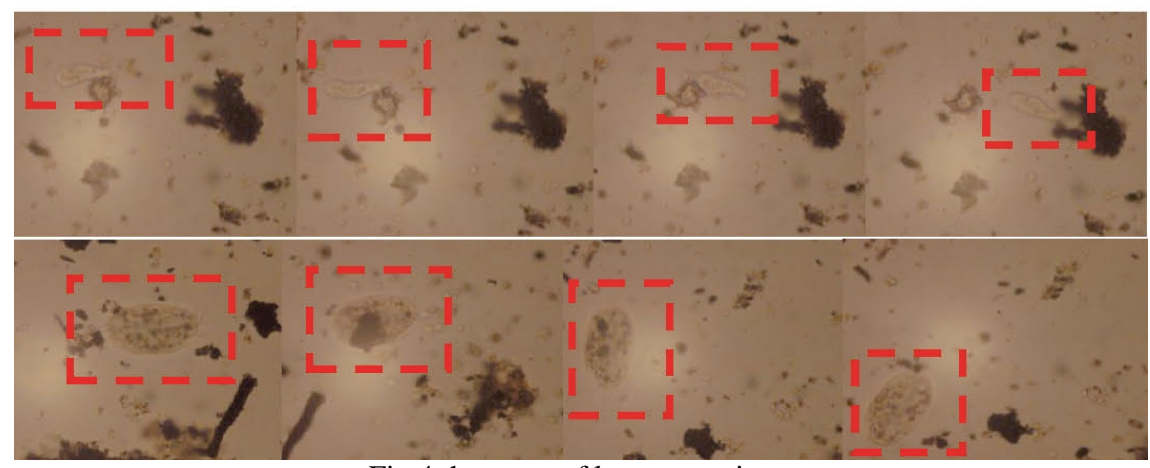

Fig.4 the route of large organisms

\section{Operation effect}

Lab-scale experiment

After seven months of dynamic running with Biological lignite coke biological filter and ceramsite filter, the results show that COD of effluent with lignite coke filter column is relatived to the minimum, which is obvious lower than that of ceramsite filter column. It can be seen from the actual running water and chromaticity index testing, the water of lignite coke aeration biological filter is low chroma, closely to colorless, and also has a better treatment effect. The main reason is that the pore structure of lignite coke hole have a larger proportion, especially for the adsorption of larger molecular weight material, making water chromaticity significantly reduced.

The figure 5 shows that processing water effect of lignite coke of biological filter column is better than the ceramsite filter column, when water within a certain range of water quality fluctuation, COD of effluent with lignite coke filter column has remained steady at around $50 \mathrm{mg} / \mathrm{L}$.

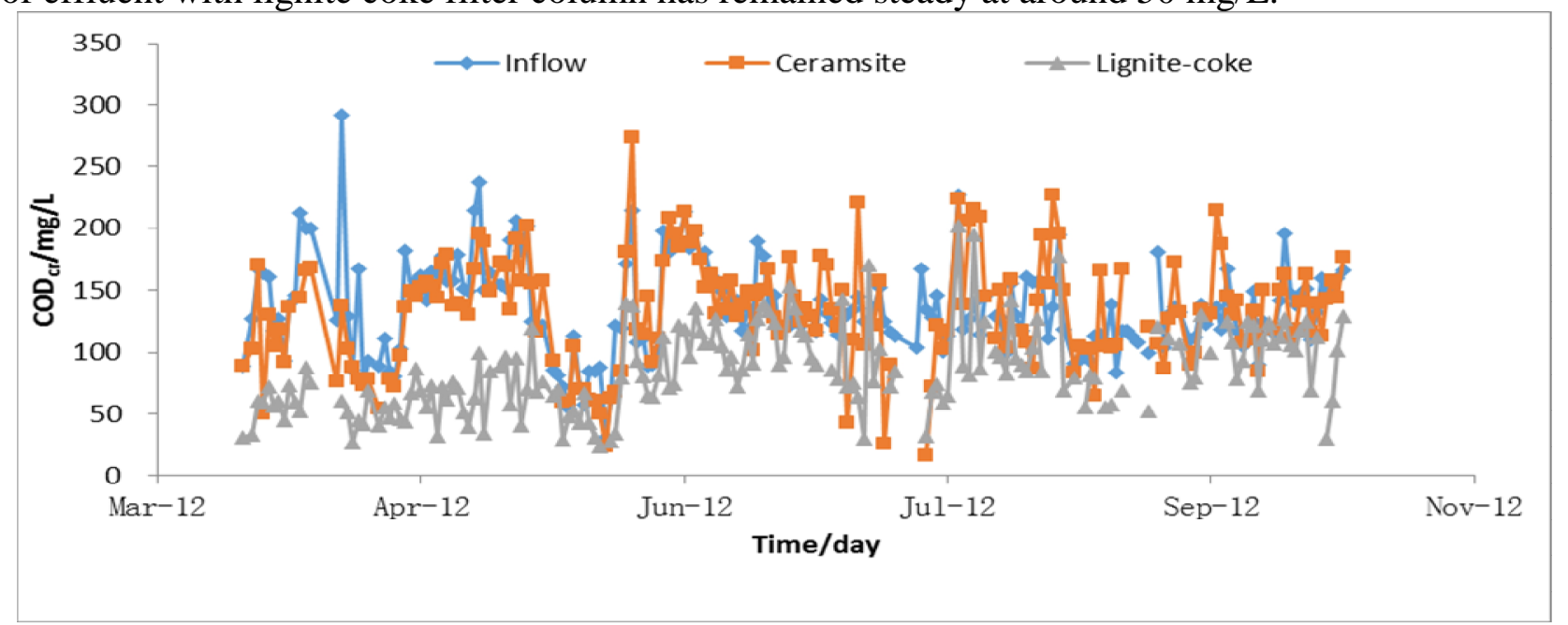

Fig.5 Change of COD in filtered water column

According to the in and out of the poor level of COD value calculation, the adsorption of lignite coke accumulated up to $20 \mathrm{mg}$ (COD)/g (lignite coke), which is obviously better than that of the ceramsite filter material.

\section{Large-scale experiment}

Start running stage to $150-200 \mathrm{~L} / \mathrm{h}$ flow of biological aerated filter for water, control of biological aerated filter inlet air flow rate is $2.0-2.2 \mathrm{~m} 3 / \mathrm{h}$, in the filter were acclimated for a period of time, according to the actual operation adjustment inlet flow rate and aeration amount gradually meet the design requirements. From Figure 6, the influent COD in $38.41 \mathrm{mg} / \mathrm{L}$ to $294 \mathrm{mg} / \mathrm{L}$ range fluctuations, the average value for the $138.9 \mathrm{mg} / \mathrm{L}$; COD of the effluent in the $14 \mathrm{mg} / \mathrm{L}$ to $158.6 \mathrm{mg} / \mathrm{L}$ range fluctuations, the average value for $81.9 \mathrm{mg} / \mathrm{L}$. According to the import and the COD value of the water margin calculation, the lignite coke cumulative adsorption amount reached the level about 22 $\mathrm{mg}(\mathrm{COD}) / \mathrm{g}$ (lignite coke). 


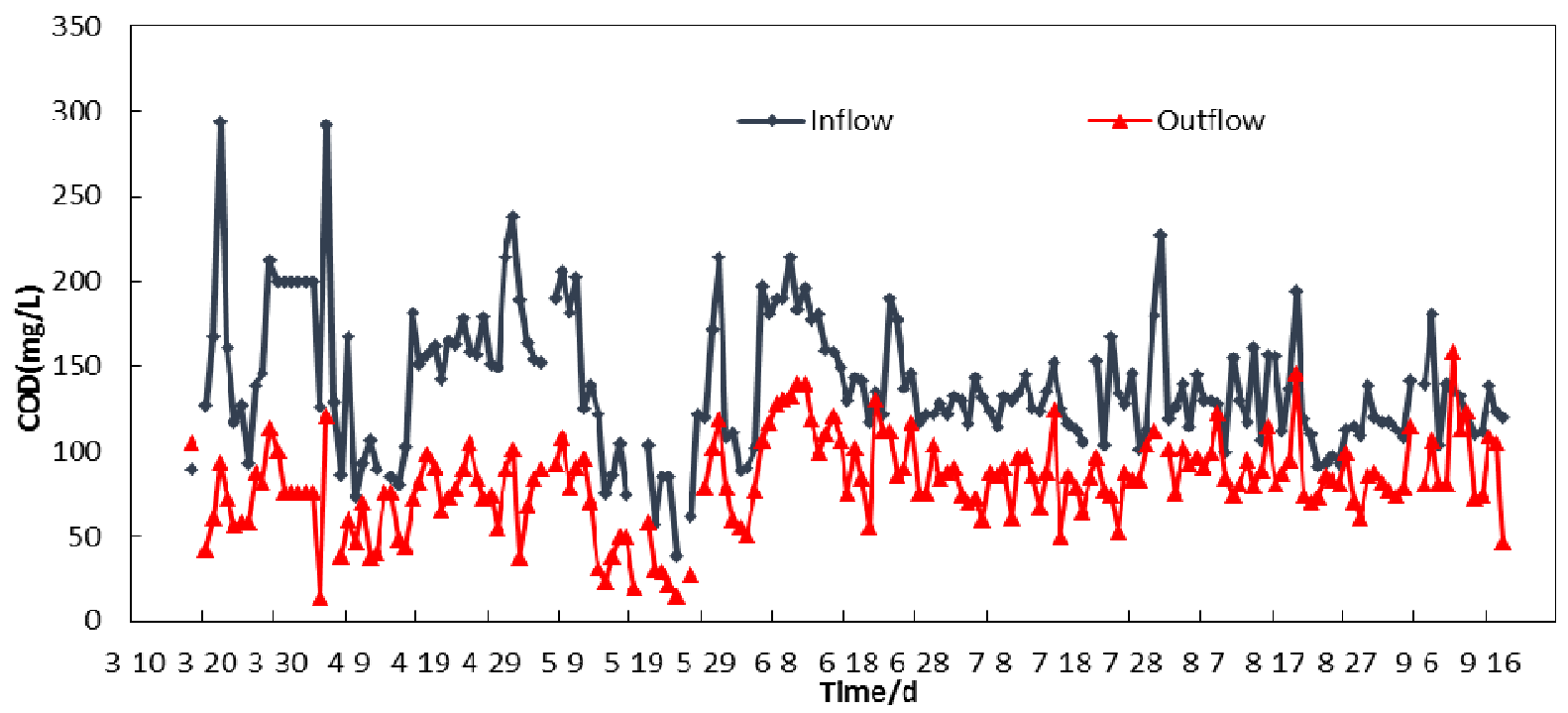

Fig. 6 the change of COD in the biological filter

The influent COD was about $100 \mathrm{mg} / \mathrm{L}$, and the effluent average value of COD was $36 \mathrm{mg} / \mathrm{L}$, the average removal rate was $60 \%$.

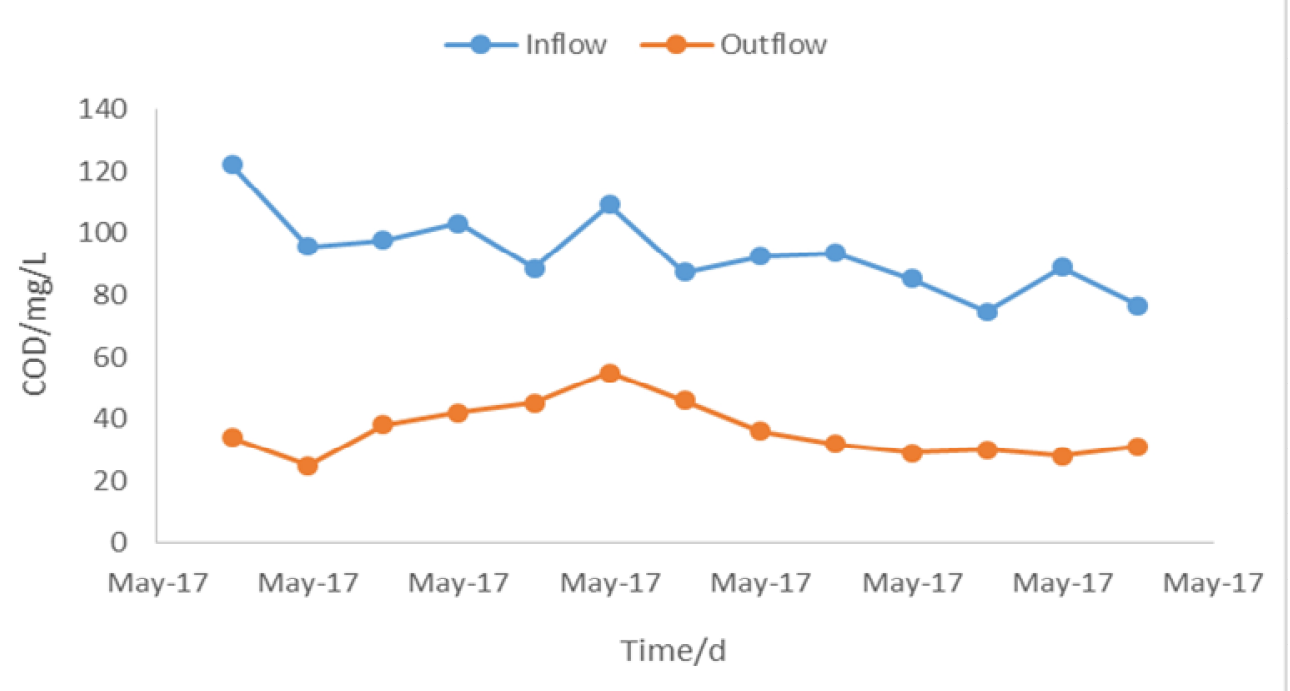

Fig.7 the change of COD content in the biological filter

\section{Operation control}

In terms of filter backwashing, of bioactive coke filter backwashing intensity and backwashing cycle do certain exploration, through the analysis of the actual situation, the backwashing parameters were that first with large volume $\left(6-7 \mathrm{~m}^{3} / \mathrm{h}\right)$ washed for $5 \mathrm{~min}$, then the gas water backwashing water $3 \mathrm{~m}^{3} / \mathrm{h}$ ) washed for $10 \mathrm{~min}$ and finally washed with water for $5 \min \left(\right.$ tap water $3 \mathrm{~m}^{3} / \mathrm{h}$ ), pre backwash cycle for 7-10 days, after stabilization phase, can maintain 20-30 days backwashing a frequency.

\section{Conclusions}

(1) For the BAF with medium of lignite coke, there has big superiority in treating secondary effluent of printing and dyeing wastewater. Not only in treatment efficiency, operational stability, but also in back flashing.

(2) Lignite coke bio-filter enhance the purification ability of activated sludge flocs by physical adsorption and biodegradation. Effluent COD and chromaticity were effectively removed, COD removal rate can reach more than $60 \%$, the system runs stable and effluent COD below $50 \mathrm{mg} / \mathrm{L}$ under the condition of volume ratio of air to water at $10: 1$, hydraulic loading $0.2 \mathrm{~m}^{3} / \mathrm{m}^{2} \cdot \mathrm{h}$. 


\section{References}

[1] Cui Fuyi, Zhang bing,Tang Li. Research and application progress of biological aerated filter technology[J]. Technology and Equipment for environmental pollution control, 2005,6 (10): 1-7.

[2] Jou CG,Huang GC.A pilot study for oil refinery wastewater treatment using a fixed-film bioreactor[J].Advanced Environment Research,2003,7:463-469.

[3] Zuo Yanbing, Yang Chunping, Zeng Guangming, et al. Advances in research on factors affecting performance of biological aerated filter [J].Environmental protection of chemical industry, 2008,28 (1): 37-41.

[4] Chang W S, Hong S W, Park J. Effect of zeolite media for the treatment of textile swmer in a biological aerated filter[J].Process Biochemistry,2002,(37):693-698.

[5] Zheng Jun, Wu Haoting, Cheng hanfei. A BAF technology and factory instance[M]. Beijing: Chemical Industry Press, 2002

[6] Okabe S, Hirata K,Watanabe Y. Dynamic changes in spatial microbial distribution in mixed-population biofilms experimental results and model simulation[J]. Water Science and Technology,1995,32(8):67-74. 